\title{
DESIGNING AND DEVELOPMENT OF A PORTABLE RICE PUFFING MACHINE
}

Sonali Biswal ${ }^{1}$, Smruti Ranjan Mohapatra ${ }^{2}$, and M.K. Panda ${ }^{3}$

\begin{abstract}
Puffed rice is a good snacks product for Odisha people. The main drawback of puffed rice is the traditional method of puffing which highly laborious, it absorbs moisture and requires a large space for the heavy and large mill set up.There is a need to design and develop a rice puffing machine for commercial applications. This project is an attempt to find a solution to prepare and serve fresh puffed rice to consumer. The objective is designing \& developing of portable rice puffing machine using the gun puffing technology by maintaining 200 psi pressure and testing the fabricated machine.This lead to mechanization of the traditional rice puffing method and reduce the heavy and tedious work. The puffed rice machine design process started with primary research and identifying the need. Data collection was carried out by adopting methodologies such as literature review, product study, process study, market study, product environment study.
\end{abstract}

Keywords: puffed rice, puffing machine, mechanization

\section{I.INTRODUCTION}

Puffed rice is a popular low cost breakfast cereal and snack used worldwide because of its ready to eat (RTE), lighter and crispness characteristics. India produces annually 89 million tonnes of rice (second largest producer of rice in the world), but, only 10 percent of it is converted to different value added products such as puffed rice, popped rice or flaked rice (Chattopadhyay, 2004). Puffed rice has got a highest demand both in national and international market. Quality factors such as uniform puffing, contamination free, good colour, crispness etc are the major concern for export of puffed rice. However, the production of puffed rice in India is only limited to village levels. The puffing method traditionally followed in India is sand-roasting. The whole process of puffing is very tedious, time consuming and involves a large amount of skilled labour working in hot conditions.

There is a need to mechanize the puffing process of rice for commercial production. Puffing of rice is done in different methods such as conduction puffing on hot sand bed (Chinnaswamy and Bhattacharya, 1983b, Srinivas and Desikachar, 1973); hot oil (Villareal and Juliano, 1987); convection heating in hot air (Chandrasekhar and Chattopadhyay, 1991); explosion puffing, employing pressure differential in a closed chamber (Villareal and

\footnotetext{
${ }^{1}$ Department of Agricultural Processing and Food Engineering College of Agricultural Engineering and Technology, Orissa University of Agriculture and Technology, Bhubaneswar, Odisha,India

${ }^{2}$ Department of Agricultural Processing and Food Engineering College of Agricultural Engineering and Technology, Orissa University of Agriculture and Technology, Bhubaneswar, Odisha,India

${ }^{3}$ Department of Agricultural Processing and Food Engineering College of Agricultural Engineering and Technology, Orissa University of Agriculture and Technology, Bhubaneswar, Odisha,India
} 
Juliano, 1987, Mariotti et al., 2006, Hoke et al., 2007) or more recently by microwave puffing (Singh and Singh, 1999, Maisont and Narkrugsa, 2010). This laborious and tedious process of conditioning necessitates replacement with a developed mechanical system to produce uniformly conditioned rice for improving puffing quality.

This study was undertaken to develop a small portable rice puffing machine for puffing and then evaluation of its puffing quality (by hot sand bed and using puffing machine).Gunpuffed whole grains are formed by cooking the grains and then subjecting them to a sudden large pressure drop. As steam under pressure in the interior of the grain seeks to equilibrate with the surrounding lower-pressure atmosphere, it forces the grains to expand quickly or "puff."

The rest of the paper is organized as follows. The materials and methods are explained in section II. Results and fabrication of the machine is presented in section III. Concluding remarks are given in section IV.

\section{MATERIALS AND METHODS}

\section{A. Properties Of Rice \& Puffed Rice-}

Moisture content A temperature controlled oven was used. The temperature was kept not higher than specified because otherwise chemical changes occur within the grain which can cause additional weight loss. The oven was set at $100{ }^{\circ} \mathrm{C}$. Three rice samples of $25 \mathrm{~g}$ weight each and along with that $5 \mathrm{~g}$ of puffed rice each was taken and placed inside the oven.The final weight of the samples was taken after 36 hours. Moisture content was calculated by weight of moisture $\left(w_{i-} w_{f}\right)$ divided by final weight $\left(\mathrm{w}_{\mathrm{i}}\right)$ of material.

$$
\mathrm{MC}_{\mathrm{db}}=\frac{w_{\mathrm{i}-w_{f}}}{w_{f}} \times 100
$$

Bulk density The bulk density is the mass of a group of individual particles divided by the total volume, including the air space.It was determined using the relationship by filling an empty plastic container or predetermined volume(1ltr) and tare weighed with the puffed rice by pouring from a constant height, striking off the top level and weighing. Then the weight of the sample was divided by volume and is expressed in $\mathrm{gm} / \mathrm{cc}$. The same process was followed for the determination of bulk density of the rice.

$$
\text { Bulk density }=\frac{\text { Weight of sample }}{\text { Volume of Sample }}
$$

True density It is the ratio of the mass of a grain sample to the solid volume occupied by the sample.True Density of rice was calculated for the rice using pycnometer and toluene displacement method.Pycnometer with stop cock was weighed in a balance (say $\mathrm{W}_{1}$ ). Then it was filled with toluene and weighed (say $\mathrm{W}_{2}$ ). The pycnometer with rice was weighed (say $\mathrm{W}_{3}$ ).Lastly pycnometer with rice and filled with toluene was weighed (say $\mathrm{W}_{4}$ ).Specific gravity of toluene was multiplied.

Sp. Gravity of liquid toluene $=0.865$ 
True density (Rica) $=\frac{\left(W_{2}-W_{1}\right)}{\left(W_{2}-W_{1}\right)-\left(W_{4}-W_{2}\right)} \times$ sp. gravity

For the true density of the puffed rice sand displacement method was used.Puffed rice was filled in a 1ltr beaker and weighed. Then the void space was filled with fine sand, sieved in a sieve of aperture size of $0.250 \mathrm{~mm}$ gauge. The sand was separated from the puffed rice and weighed.True volume of puffed rice was obtained by measuring the volume of puffed rice with void space filled with fine sand and substracting the volume of the separated sand. Then the weight taken was divided by the volume of the container to obtain the true density.

True density (puffed rice) $=\frac{\text { weight of samplt }}{71-v^{2}}$

Where,

Volume of puffed rice (v1)

Volume of fine sand (v2)

Porosity is a property of grain that depends on its bulk and kernel densities. $\varepsilon$ is the percentage of air between the particles compared to a unit volume of grains and it was computed as:

$\varepsilon=\frac{p_{r}-p_{b}}{f_{\mathrm{s}}} \times 100$

Where,

$\rho_{\mathrm{t}=}$ true density

$\rho_{\mathrm{b}}=$ bulk density

The percentage of puffing was determined by the ratio of number of rice puffed to the number of actual pre-conditioned rice taken for puffing multiplied by 100 .

Percent of Puffing $=\frac{N_{p c}-N_{u_{p}}}{N_{p \varepsilon}} \times 100$

Where, $\mathrm{N}_{P C}$ and $\mathrm{N}_{u p}$ correspond to numbers of initial grains and number of un-puffed grains (remained unpuffed during puffing) respectively.

Expansion ratio (er) The expansion ratio was determined by taking the ratio of the bulk density of rice to that of the expanded product (Puffed pregelatinized rice flour H.-M. Lai and H.-H.Cheng.)

Textural analysis Samples of puffed rice were taken and tested for determining the crispiness of puffed rice by bulk compression.

Sample Preparation by taking samples of puffed rice and removing from the place of storage just prior to testing and weighed into equal portions. It is important that this weighed amount is enough to approximately fill the Ottawa cell.35mm Cylinder Probe (P/35) using 50kg load cell was used.Two pellets were positioned, centrally under the probe.The compression test was commenced for ten samples of rice and puffed rice sample. 


\section{B. Development of portable rice puffing machine-}

From review of literature about gun puffing it was found that rice with $9 \%$ m.c. can be puffed instantaneously by heating inside a closed container up to 250psi. The science behind it was increasing the pressure upto a certain pressure and then releasing it instantaneously. Based on the idea from review of literature, attempt was made to fabricate a portable gun puffing machine with the dimension given as per figure 1 .

Materials used for fabrication Hollow iron cylinder, Ms flat, Rounded bars, Nuts \& bolts, Pressure gauge, Angle bars.

Considering the pressure for puffing as 200 psi \& factor of safety as 2 , the thickness of the barrel was calculated as :

$$
t=\frac{P * D}{2 * f * j}
$$

Where, $\mathrm{t}=$ thickness of barrel

$\mathrm{P}=$ design pressure

$\mathrm{D}=$ diameter of barrel

$\mathrm{f}=$ allowable stress of material

$j=$ weld factor

The pressure puffing of rice was proposed and the following drawing was made.The puffing machine drawing was given to the lathe workshop in Bhubaneswar for fabrication purpose.

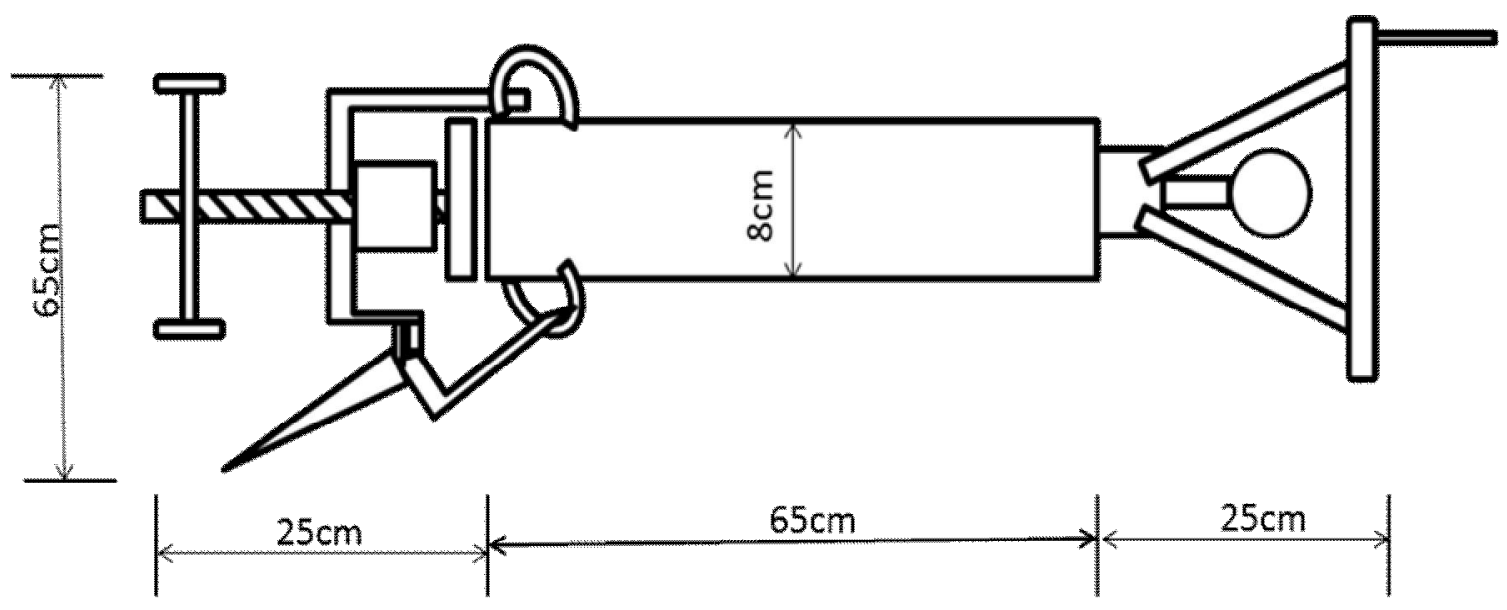

Figure1. Layout of the proposed Rice Puffing machine

Materials required for the purpose and the cylinder of which the chamber was to be made of was given to the foreman of the workshop, Bhubaneswar.Further fabrication started as shown in figure $2 \& 3$. The facing of the cylinder was done \& a circular MS flat was welded at the circumference. The back side was closed $\&$ a round bar threaded $\&$ drilled for attachment of pressure gauge. The cover was made with a hub type attachment for locking the cover also a hook type arrangement is made. A base is made up of joining the angles \& then a bush is 
made of $360^{\circ}$ rotation \& twisting type in one side \& another side a " $U$ " shaped platform. All parts were assembled.The chamber was checked for the leakage by putting some carbide and water, which produces an exothermic reaction and a gas releases showing a leakage. Hence it was again grooved and a wore ring was placed. The same test for leakage was tested and found no leakage.

Overall dimensions:

Length of cylinder $=65 \mathrm{~cm}$

Thickness of cylinder $=0.8 \mathrm{~cm}$

Circumference $=48 \mathrm{~cm}$

Handle $=44 \mathrm{~cm}$

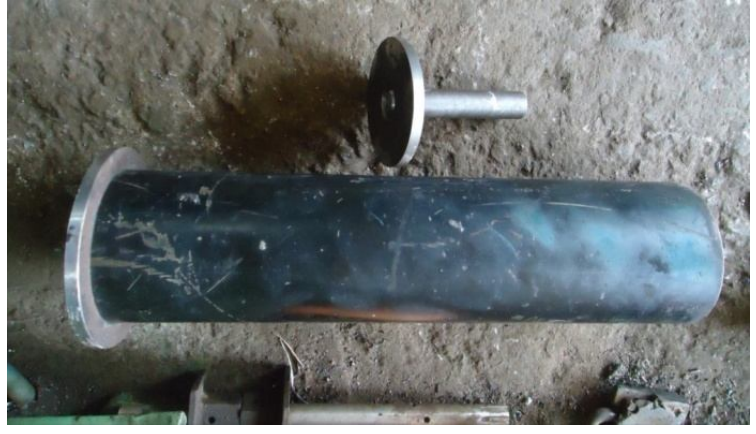

(a)

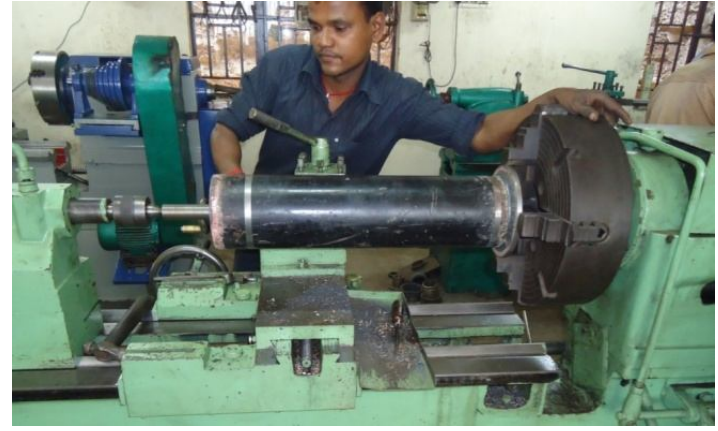

(b)

Figure 2. (a) Development of barrel (puffing chamber) (b) Threading for pressure gauge attachment
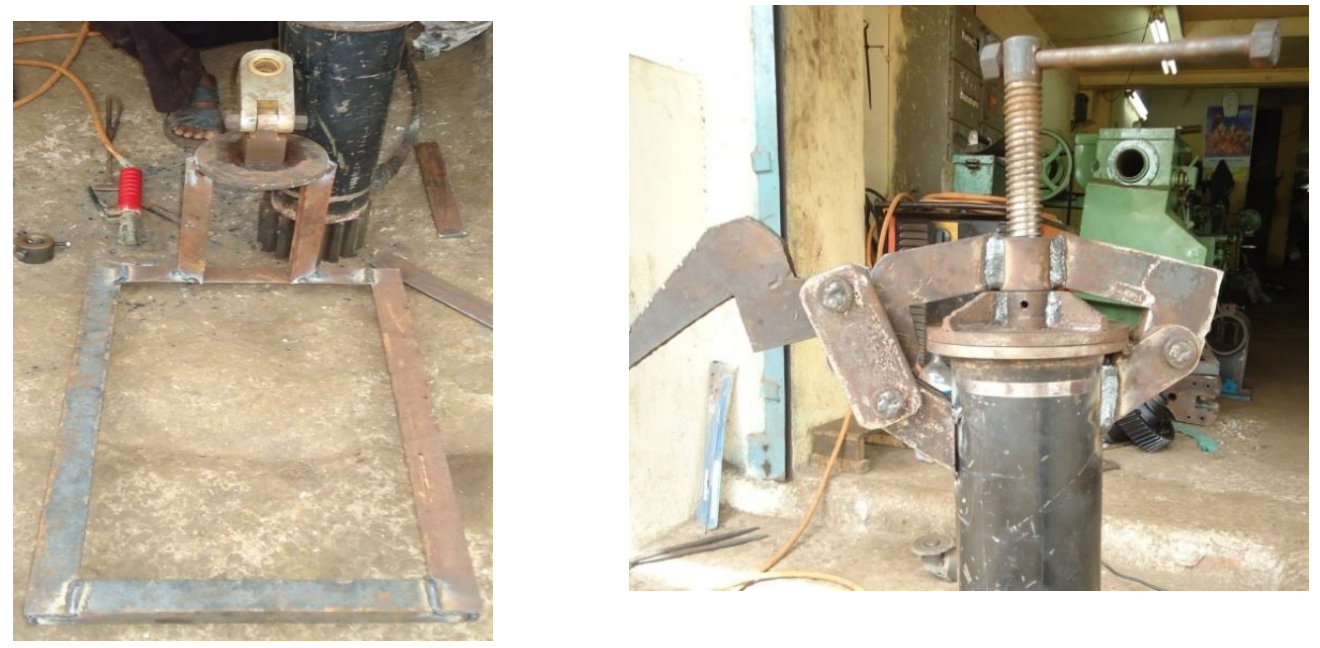
(a)

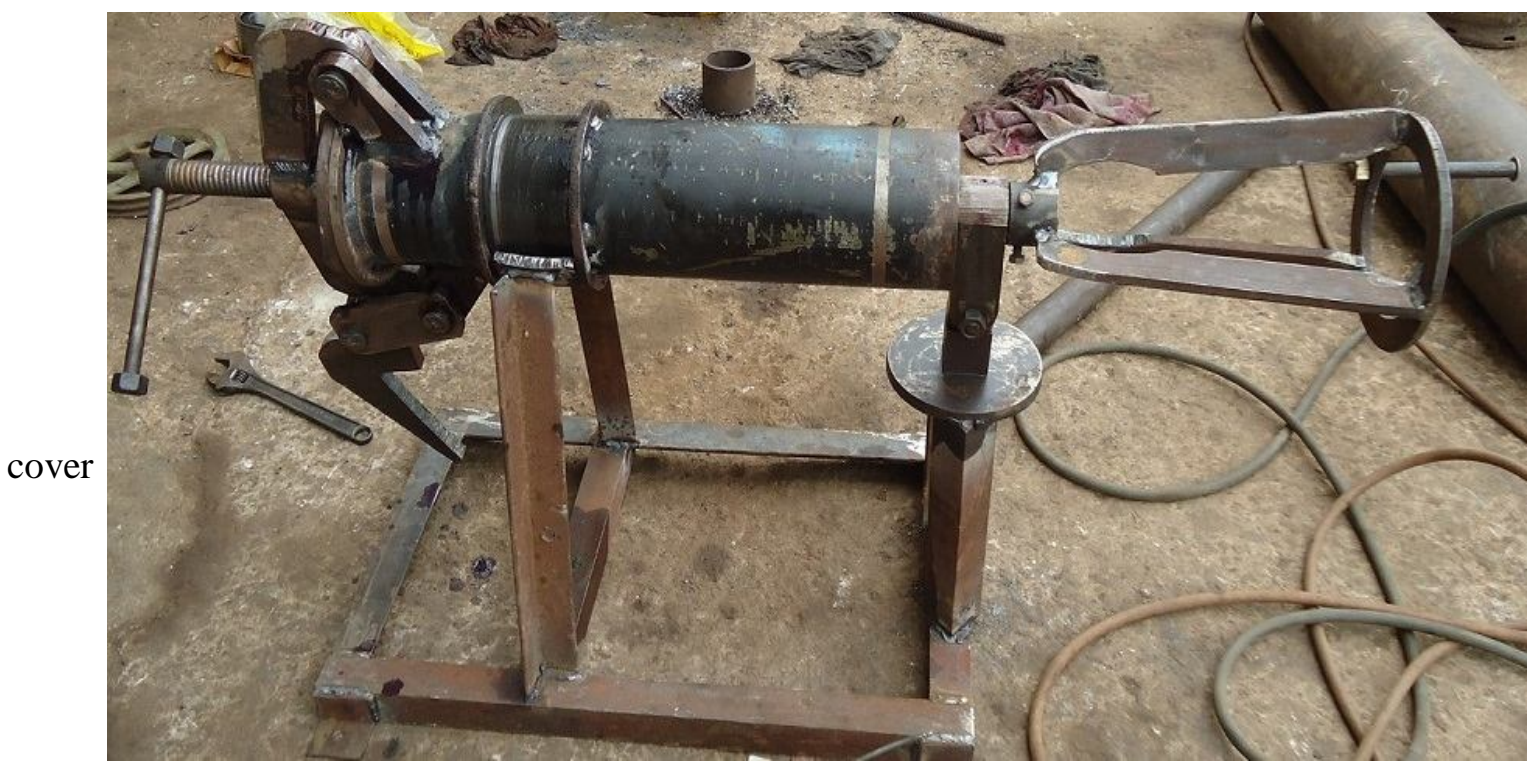

(c)

Figure 3. (a) Development of resting stand (b) Locking mechanism of cover (c)The fabricated rice puffing machine

The conditioned rice was loaded into the opening of the gun and the lid was closed and sealed. The was gun rotated over the gas burners, heating the sides of the gun body causing the moisture in the grain to convert into steam. When the lid was opened, due to the sudden change in pressure in the ambient atmosphere, it causes the rice to expand and puff.

The pretreated rice or control sample (Raw) was puffed by using the rotating rice puffing gun.

i. The rice was heated until the gauge pressure of the gun chamber reached about 50 psi which took about $15 \mathrm{~min}$. The lid was quickly removed to release the pressure.

ii. Again the rice was refilled inside, but the pressure increased to 190 psi. hence after 5 minutes of heating the lid was removed obtaining puffed rice and all the properties of the puffed rice was determined .

\section{RESULTS AND DISCUSSION}

The quality characteristics were compared between the puffed samples obtained by traditional method of hot sand bed puffing and by developed rice puffing machine. The average values of all parameters are compared in Table 1. It revealed that puffing quality 
obtained with two methods was comparable to each other (non-significant difference). The Expansion of puffed rice volume were achieved more than 6.30 in both the puffing methods which is desirable for puffed cereals. Thus, it could be concluded that, the machine could be utilized for production of puffed rice reducing the heavy work in traditional method.

Table 1. Comparison of properties of puffed rice obtained from traditional method and puffing machine

\begin{tabular}{|l|l|l|}
\hline Parameter & Traditional method & $\begin{array}{l}\text { Rice puffing } \\
\text { machine }\end{array}$ \\
\hline Moisture content (\%) & 6.75 & 5.16 \\
\hline Bulk Density(g/cc) & 0.0975 & 0.105 \\
\hline True Density(g/cc) & 0.39 & 0.48 \\
\hline Porosity(\%) & 75 & 68.3 \\
\hline Toughness(g-sec) & 120019.689 & 87335.01 \\
\hline Fracturability(g-sec) & 121268.189 & 104405.949 \\
\hline Crispness(g-sec) & 40 & 42 \\
\hline Puffing percentage & 68 & 57 \\
\hline Expansion ratio & 8.54 & 7.89 \\
\hline
\end{tabular}

\section{CONCLUSION}

A gun puffing machine having volumetric capacity of $3265.6 \mathrm{~cm}^{3}$ and capable of obtaining 300 psi was developed. The rice puffing machine was able to produce puffed rice with preconditioned rice grains with required degree of expansion ratio and puffing percentage. This machine would help in reducing the labourous and time taking process of the traditional method and would help in reducing the space of work as this requires limited space for work.Different methodologies adopted in this project were very useful for the execution of the project in terms of collecting data, analyzing the data, and creating concepts. Different concepts were generated and analysed, after filtering one of the concepts were chosen for final validation and testing.Further modifications are expected for better performance of the rice puffing machine and standardising the temperature and pressure parameters are required for enhancing the efficiency of the machine.

\section{REFERENCES}

[1] Chandrasekhar PR and Chattopadhyay PK, "Heat transfer during fluidized bed puffing of rice grains", $J$ Food Process Engg. 11:147-157, 1989.

[2] Chandrasekhar PR and Chattopadhyay PK, "Rice puffing in relation to its varietal characteristics and processing conditions", J Food Process Engg. 14: 261-277, 1991.

[3] Chattopadhyay P K, " Post harvest technology for rice in India: A changing scenario", In : Rice is life: Scientific Perspectives for the 21st Century,

[4] Toriyama K, Heong K.L, Hardy B., (Eds.). Proceedings of the World Rice Research Conference held in Tokyo and Tsukuba, Japan, 4-7, November 2004. Los Baños, Philippines, pp., 294296 
[5] Chinnaswamy R and Bhattacharya KR," Studies on expanded rice, physico-chemical basis of varietal differences" J Food Sci. 48: 1600-1603, 1983.

[6] Chinnaswamy R and Bhattacharya KR, "Studies on expanded rice, optimum processing conditions", $J$ Food Sci. 48: 1604-1608

[7] Maisont S and Narkrugsa W, "Effects of salt, moisture content and microwave power on puffing qualities of puffed rice.", Kasetsart J Natural Sci. 44(2): 251261, 2010.

[8] Mohapatra M. and Das S.K., "Mechanizing the conditioning process of rice before puffing", Oryza Vol. 48 No. 2, 2011.

[9] Mariotti M, Alamprese C, Pagani MA and Lucisano M, "Effect of puffing on ultrastructure and physical characteristics of cereal grains and flours. J Cereal Sci. 43: 47-56,2006.

[10] Singh J and Singh N, "Effects of different ingredients and microwave power on popping characteristics of popcorn", J Food Engg. 42: 161-165,1999.

[11] Srinivas T and Desikachar HSR, "Factors affecting the puffing quality of paddy", J Sci. Food Agric. 24 : $883-891,1973$.

[12] Villareal CP and Juliano BO," Varietal differences in quality characteristics of puffed rice", Cereal Chem. 64 : 337-342,1987. 